\title{
A Epidemiologia Salvou-se por Milagre, mas a Saúde Pública Soçobrou
}

José da Rocha Carvalheiro*

\section{A Epidemiologia está dando os números}

Ainda não passou de todo, mas abrandou-se muito a sofreguidão com que se apontou a epidemiologia como salvadora da saúde pública. Identificando-a como a única disciplina capaz de dar racionalidade ao funcionamento dos serviços, procurou-se introduzi-la à força na cabeça dos profissionais que aí atuam. A vida real incumbiu-se de mostrar que a razão técnica (epidemiológica) dificilmente supera as outras: administrativa, econômica, política (TESTA, 1992).

Fracassado o intento por essa via unidirecional, escolheu-se outra, o planejamento. Planejados, os serviços funcionam, eis a nova razão técnica. Desta vez fadada ao sucesso: o planejamento inundava todos os setores, a saúde não podia escapar. Também não deu certo. Da mesma forma que ocorrera com a epidemiologia, também o planejamento não se implantou a sério. Apesar dos esforços para contextualizá-lo em situações concretas, quando apontaria estratégias de ação.

Por ensaio e erro, chegou-se à investigação. É preciso ensinar o pessoal de serviço a investigar. Suas próprias rotinas podem ser alteradas se submetidas ao crivo da pesquisa. Esta nova panacéia encontra ainda forças para prosperar. Existe uma rede internacional de investigação em serviços e sistemas de saúde que edita boletins, promove reuniões, financia modestos projetos nos países pobres. O resultado desta pesquisa peculiar não é obrigatoriamente uma publicação científica, mas um sumário executivo apresentado ao dirigente encarregado da tomada de decisões. Necessariamente sucinto, afinal é um sumário e, ade-

* Diretor do Instituto de Saúde - SESP/SP

Professor Titular da FM de Ribeirão Preto-USP 
mais, dirigido a pessoa tão atarefada que não tem tempo de ler mais que algumas poucas linhas. A razão instrumental encontra aqui quase seu valor supremo.

Vinda "pela noite tão longa de fracasso em fracasso", à Saúde Pública, "cansada de tudo", só parecia "restar o cansaço". Ao contrário da canção famosa, a saúde pública não envelhece, nem chega ao fim. O sentido da sua crise é o de um prenúncio de solução, renasce continuamente a esperança de que os novos caminhos são sempre mais radiosos. Em cada uma das tentativas mencionadas sempre se conseguiram avanços. A epidemiologia, o planejamento, a investigação, não resolveram a situação mas, bem ou mal, implantaram-se nos serviços e nos sistemas de saúde. Não há como negar. $\mathrm{O}$ que, sim, se nega é a idéia ingênua de que intervenções singulares na instância técnica resolverão sozinhas a crise profunda que se abateu sobre a saúde pública em nível mundial. Também aqui identificamos o crescente processo de globalização ou mundialização: a coca-cola, o "big-mac" e a saúde em crise estão em toda a parte : na China e na Chechênia, mas também nos EUA, na Bélgica e na Índia. Para não mencionar o Brasil.

A epidemiologia salvou-se do naufrágio de uma maneira singular. Aliás, ressalte-se que a própria saúde pública volta à tona, ainda que adernada. As novas "vertentes" da epidemiologia dão-lhe um vigor inesperado. A epidemiologia clinica, originalmente concebida para ilustrar clínicos e cirurgiões de grande prestígio que sistematicamente são escolhidos para dirigir a saúde pública (MORROW \& BUCK, 1983), fracassa como movimento ideológico. Mas encontra seu nicho a nível dos serviços, especialmente nos hospitais, avançando no terreno da avaliação de procedimentos terapêuticos e testes diagnósticos e no delineamento de prognósticos. A epidemiologia social avança de forma fantástica num sentido epistemológico, dando à disciplina uma consistência teórica e metodológica nunca antes alcançada. A epidemiologia molecular, em sua aplicação diagnóstica imediata e sua inserção num arcabouço teórico mais sofisticado (epidemiologia evolutiva), representa um elemento novo e de grande significado.

Já nem me lembro se a origem é italiana ou espanhola. Usava-se no Brás e na Moóca, e também no Ipiranga, bairros tradicionais da cidade de São Paulo. Quando uma pessoa ficava meio louca, dizia-se: fulano está dando os números. Considero ocioso o debate sobre uma epidemiologia com números ou sem números. Prefiro pensar que a epidemiologia está dando os números: uma loucura branda, lúcida, versátil e, sobretudo, produtiva.

\section{Município global ou Mundo municipal?}

Existem duas tendências atuais, de extraordinária relevância e incrivelmente contraditórias, que se impõem ao atônito cidadão comum: a globalização e a municipalização.

A globalização ou mundialização crescente da economia, especialmente da produção e do sistema financeiro (COMISSÃO SUL, 1990), mas também do 
consumo e da informação, tem que ser encarada com a maior seriedade. Representa, antes de tudo, para os cientistas, um desafio teórico, metodológico e epistemológico. Como interpretar as novas realidades, com o aparente fim de ciclo dos estados-nação? A Comissão Sul, presidida por Julius Nyerere, da Tanzâia, analisa a questão em seu relatório final $O$ desafio do Sul. Contava com vinte e oito membros, oito latino-americanos, sendo dois brasileiros: Paulo Evaristo Arns e Celso Furtado. Preocupada com a crescente marginalização do hemisfério sul, debruça-se sobre o caráter assumido pela globalização. Identifica a formação de blocos regionais com intenção deliberada de criar espaços econômicos maiores e mais fortes. No âmbito da cultura, a revolução das comunicações representa uma invasão sem migrações, do sul pelo norte, de muito maior impacto do que o representado pelas correntes migratórias em sentido inverso. Aliás, esta intensa movimentação internacional de pessoas é outro aspecto marcante no processo. A degradação do ambiente também não pode ser encarada senão em âmbito global. O mesmo seja dito para o tráfico de drogas ilícitas e a corrupção. Na área da saúde, a erradicação da varíola e outras propostas semelhantes e, mais ainda, as propostas de controle da epidemia de AIDS só podem mesmo ser pensadas globalmente.

Contraponto à globalização é representado pela evidência de que o exercício da cidadania está na radicalização da democracia. Um meio termo entre uma democracia representativa e outra participativa, ou direta,. exige uma radicalização da participação da sociedade a nível local, municipal no caso brasileiro. $\mathrm{O}$ cidadão comum não vai exercitar seus direitos no Mercado Comum Europeu, no NAFTA ou no MERCOSUL. Vai fazê-lo, em tendo consciência, no bairro ou no município. Se o objetivo é o bem estar, o âmbito em que este é conseguido é no micro ambiente imediato e não num etéreo mundo globalizado. Nesta complexa dialética, o mínimo tangência o máximo! O maior desafio é precisamente a construção de uma globalização, fortemente impulsionada pelo vertiginoso crescimento da tecnologia, que consista na melhoria das condições de vida nos locais singulares onde as pessoas vivem.

\section{A crise da saúde é mundial}

O mesmo debate, que se propõe em outros setores, atinge também o da saúde. Pensar alternativas à abordagem clássica da saúde internacional é imperioso. Nos países do norte, especialmente nos EUA, a saúde internacional é geralmente tratada apenas como um esforço de proteção nacional contra a invasão de doenças já controladas. Rígidos mecanismos de vigilância epidemiológica, no âmbito do Regulamento sanitário Internacional, são resíduos das propostas de quarentena que no passado foram sempre impostas pelos mais fortes, freqüentemente atendendo mais aos interesses comerciais do que aos sanitários. 
Em recente trabalho, FERREIRA et al (1992) procuram ultrapassar esta visão estritamente destinada à proteção dos interesses do hemisfério norte. Pensando a saúde num mundo globalizado, identificam fatores que influenciam os sistemas de saúde nos países, para além do próprio conflito norte-sul. Detêm-se particularmente: nos problemas de financiamento do sistema; na medicalização; nas relações assimétricas entre categorias profissionais da área da saúde; na limitação das propostas de melhoria que culpabilizam as vítimas, considerando os estilos de vida como se fossem opções individuais e não construções sociais dos padrões de consumo; na introdução indiscriminada da tecnologia médica; nas tentativas de resolver por critérios biomédicos, problemas sociais resultantes de determinantes sócio-econômicos, riscos ambientais e da própria atomização do sistema de saúde.

As bandeiras desfraldadas pelo movimento sanitário mundial, capitaneado pela própria OMS, estão em frangalhos. O brado saúde para todos, consubstanciado na sigla SPT/2000, estabelece a chegada do século XXI como limite temporal ético para atingir universalmente os melhores níveis de saúde possiveis. Mesmo com todas estas limitações, o limite foi mudado para o quanto antes. $\mathrm{O}$ que poderia dar a entender que mesmo antes do ano 2000 a eqüidade em saúde poderia ser atingida, falácia até mesmo para uma coisa aparentemente mais simples como a eqüidade no acesso aos serviços.

Os interesses mercantis caminham com desenvoltura muito maior. A OMS não conseguirá chegar à SPT/2000, mas algumas empresas privadas já anunciam que isto é possível para alguns, em qualquer lugar deste maravilhoso mundo globalizado. Uma delas, em anúncio largamente difundido na televisão comercial brasileira, oferece os serviços de um enfermeiro alemão de múltiplas competências. Pelo tom da propaganda, não existe donzela neste país que não queira quebrar uma perna no exterior, só para ser atendida por ele. Desde, é claro, que pague o seguro privado que fez o anúncio.

\section{A epidemiologia faz do distrito a sua moradia}

Cansada de tanto "dar os números", a epidemiologia resolveu comportarse. Após andar por ceca e meca e olivais de santarém, buscou refúgio nos distritos sanitários para alí, operacionalizar uma modesta proposta de análise da situação de saúde, segundo condições de vida.

Aproveitou-se, na verdade, da transformação operada no próprio âmbito da proposta SPT/2000. A sintonia fina mostrou que o caminho estava na Atenção Primária em Saúde (APS), na construção dos Sistemas Locais de Saúde (SILOS) e Distritos Sanitários. É, de novo, a globalização buscando suporte no âmbito de elementar, do local, do municipal. A busca da eqüidade passa pela proposta das novas ações de saúde a nível dos distritos (WHO, 1992). 
Num processo aparentemente simples, mas de extrema complexidade pelo vulto do entulho a remover, procura-se definir sistemas de informação adequados ao uso da epidemiologia na proposição de ações concretas. $O$ fluxo das informações no sistema de saúde pode ter dois sentidos: ascendente e descendente. Atendem a interesses que se complementam mas conduzem a arquiteturas distintas do sistema de informações. $O$ planejamento central das ações de saúde, a nível nacional, exige níveis de agregação dos dados absolutamente inúteis para o exercício das ações a nível local. Para estas, o fluxo ascendente é o essencial. Dados buscados na própria comunidade são os únicos que permitem a micro-localização dos fenômenos ligados à saúde e, portanto, as propostas de ação. Se não forem agregados, estes dados serão inúteis para o nível central. A tendência atual é definir operacionalmente o Distrito Sanitário, do ponto de vista do sistema de informações, como o local de encontro dos fluxos ascendente e descendente (WHO, 1994). Aqui deve localizar-se a unidade de análise, com forte conteúdo epidemiológico.

A micro-localização das necessidades, ou a abordagem da situação de saúde, segundo condições de vida, evoluiu com rapidez nos últimos anos. Técnicas simplificadas de estimativas rápidas são complementadas, às vezes pela utilização de avanços da informática, como o geoprocessamento. De maneira simples, manual, ou sofisticada pelo uso de microcomputadores, definirem-se necessidades pela óptica dos técnicos ou da população (inquéritos de opinião). Problematizar as questões de saúde, ou transformar necessidades em problemas exige também a utilização de mecanismos apropriados. Métodos qualitativos como os Grupos Focais são importantes, mas insuficientes. Captam as representações, mas não permitem avançar se não forem encontrados outros canais mais formais de controle social. Uma participação efetiva da população apenas se viabiliza pela criação de Conselhos com poder deliberativo e capazes de controlar a utilização dos fundos públicos destinados à saúde. Os riscos do corporativismo e os da transformação destas instâncias em locais de confronto político, ideológico ou mesmo partidário são inevitáveis. Mas este é, inegavelmente, o local adequado a sua explicitação e equacionamento.

Entendida como razão técnica, a epidemiologia joga aqui um papel fundamental, quando outras razões estão presentes.

\section{Cada um com o seu}

O discurso precedente conduz a uma estranha sensação reotáxica: a saúde nadando contra a corrente. À tendência globalizante, contrapõe-se uma proposta de fragmentação. Como negar a negação?

O processo de implantação do SUS nos quase seis mil municípios brasileiros é exemplar. À absurda generalização da idéia da falência completa do siste- 
ma público, contrapõem-se dezenas, ou mesmo centenas, de experiências bem sucedidas, às quais não se tem dado a divulgação necessária. Não podemos considerar a implantação do SUS como processo isolado. É o exemplo atual mais fascinante de tentativa de construção da cidadania no Brasil. Organizar a saúde no âmbito dos distritos sanitários tem forte interação dialética com outros recortes, nacionais e internacionais, tanto no âmbito da saúde quanto no âmbito social, econômico e político mais geral.

No meu entender, a chave para esta superação dialética veio de uma fonte inesperada. Apontando para a obrigação de se respeitar a diversidade, e com espantosa candura, uma adolescente escolhida como madrinha da bateria da Escola de Samba Mangueira, no Carnaval de 1995, entrevistada, saiu-se com uma frase definitiva: "Eu sou da comunidade. Outras escolas escolheram atrizes, modelos e vedetes. Não tenho nenhuma crítica pois acho que, no Carnaval, é cada um com seu cada qual".

\section{Referências Bibliográficas}

- COMISSÃO SUL O desafio ao sul. Edições Afrontamento, Porto, 1990

- FERREIRA,J.R.; GODUE,C.;NERVI,L.\&RODRIGUEZ,M.I. Overview of the Quebec Meeting in PAHO(1992) International Health, a northsouth debate, , Washington, 1992. (Human Resources Development Series $N^{\circ}$ 95)

- MARROW,R.H. \& BUCK,C. Clinical epidemiology for developing countries, Int. J. Epidemiol. 12:3-4, 1983.

- TESTA,M. Pensar em saúde. Porto Alegre, Artes Médicas,. 1992

- WORLD HEALTH ORGANIZATION A call for new public health action (Report of the Saitama Public Health Summit), Geneva, 1992. WHO/HRH/92.1.

- WORLD HEALTH ORGANIZATION Information Support for new public health action at district level. Geneva. 1994 (WHO- Techn. Rep. Series, 845) 